\title{
Specificity of Afferent Synapses onto Plane-Polarized Hair Cells in the Posterior Lateral Line of the Zebrafish
}

\author{
Aaron Nagiel, Daniel Andor-Ardó, and A. J. Hudspeth \\ Howard Hughes Medical Institute and Laboratory of Sensory Neuroscience, The Rockefeller University, New York, New York 10065-6399
}

\begin{abstract}
The proper wiring of the vertebrate brain represents an extraordinary developmental challenge, requiring billions of neurons to select their appropriate synaptic targets. In view of this complexity, simple vertebrate systems provide necessary models for understanding how synaptic specificity arises. The posterior lateral-line organ of larval zebrafish consists of polarized hair cells organized in discrete clusters known as neuromasts. Here we show that each afferent neuron of the posterior lateral line establishes specific contacts with hair cells of the same hair-bundle polarity. We quantify this specificity by modeling the neuron as a biased selector of hair-cell polarity and find evidence for bias from as early as $2.5 \mathrm{~d}$ after fertilization. More than half of the neurons form contacts on multiple neuromasts, but the innervated organs are spatially consecutive and the polarity preference is consistent. Using a novel reagent for correlative electron microscopy, HRP-mCherry, we show that these contacts are indeed afferent synapses bearing vesicle-loaded synaptic ribbons. Moreover, afferent neurons reassume their biased innervation pattern after hair-cell ablation and regeneration. By documenting specificity in the pattern of neuronal connectivity during development and in the context of organ regeneration, these results establish the posterior lateral-line organ as a vertebrate system for the in vivo study of synaptic target selection.
\end{abstract}

Key words: acousticolateralis system; eighth nerve; fluorescent protein; hair cell; planar cell polarity; ribbon synapse

\section{Introduction}

Our perception of environmental stimuli depends critically on the ability of developing neuronal processes to obey guidance cues, recognize appropriate targets, and synapse with particular cells (Goodman and Shatz, 1993; Benson et al., 2001). Although much progress has been made in understanding the first two steps (Dickson, 2002), how neurons decide to form stable synapses with particular target cells remains unclear.

The lateral-line organ of larval zebrafish possesses a number of qualities that facilitate the study of this question. Lateral lines enable certain aquatic vertebrates to sense water currents and thus aid in prey capture, predator avoidance, rheotaxis, and shoaling (Montgomery et al., 1997). The functional unit of the lateral line is the neuromast, which consists of superficial hair cells ensheathed by supporting cells, surrounded by mantle cells, and innervated by afferent and efferent neurons (Metcalfe et al., 1985). The cell responsible for the detection of mechanical stim-

\footnotetext{
Received May 29, 2008; revised July 10, 2008; accepted July 11, 2008.

This work was supported by National Institutes of Health Grants DC00241 and DC07294 and Medical Scientist Training Program Grant GM07739. A.N. is the recipient of Ruth L. Kirschstein National Research Service Award Predoctoral Fellowship NS62486. A.J.H. is an Investigator of Howard Hughes Medical Institute. We thank A. Afolalu for expert fish husbandry, Dr. P. Brehm for the islet1:GFP fish, Dr. A. Chitnis for the HuC:GFP fish, Dr. H. Baier for the Brn3c:gap43-GFP fish, the Zebrafish International Resource Center for the neurogenin 1 mutant fish, Dr. S.-I. Higashijima for the HuC:GFP CDNA, Dr. P. Ortiz de Montellano for the HRP-C CDNA, Dr. A. North for assistance with the spinning-disk microscope, and Drs. E. Fuchs and A. Pasolli for access to the transmission electron microscope. Dr. E. Gonzalez, J. A. Robbins, Dr. M. Schober, and the members of our research group provided helpful comments on this manuscript.

Correspondence should be addressed to Dr. A. J. Hudspeth, Howard Hughes Medical Institute and Laboratory of Sensory Neuroscience, The Rockefeller University, Campus Box 314, 1230 York Avenue, New York, NY 10065-6399. E-mail: hudspaj@rockefeller.edu.

DOI:10.1523/JNEUROSCI.2425-08.2008

Copyright $\odot 2008$ Society for Neuroscience $\quad$ 0270-6474/08/288442-12\$15.00/0
}

uli is the hair cell, which bears on its apical surface a hair bundle that transduces mechanical deflections into electrical signals (Hudspeth, 1989). The hair bundle comprises a staircase-like arrangement of actin-filled stereocilia and a true cilium, the kinocilium, which stands at the tall edge (see Fig. 1C). Hair-bundle deflections toward the kinocilium depolarize the hair cell, whereas movements in the opposite direction hyperpolarize it (Shotwell et al., 1981). Membrane depolarizations trigger the release of neurotransmitter from the cell's base at presynaptic specializations known as synaptic ribbons (Keen and Hudspeth, 2006).

A striking feature of the lateral line is the planar polarization of hair cells within a neuromast (Flock and Wersäll, 1962), which is manifested in two ways. The first is the aforementioned hairbundle polarity, which defines the vector of mechanosensitivity and is intrinsic to each hair cell. The second manifestation of polarity, which is governed by the planar-cell-polarity pathway, arises from the coordinated orientation of polarized hair bundles with respect to the bodily axes (López-Schier et al., 2004). The bilaterally symmetrical lateral-line system of a larval zebrafish has two components, each containing approximately 10 neuromasts: an anterior lateral line covering the head and a posterior lateral line (PLL) along the trunk and tail (Metcalfe et al., 1985). Each neuromast contains two sets of hair cells of opposite hair-bundle polarities disposed across a plane of mirror symmetry (LópezSchier and Hudspeth, 2006). In the PLL, most neuromasts contain anteriorly polarized hair cells and posteriorly polarized hair cells, whereas a few specific neuromasts contain dorsally polarized and ventrally polarized hair cells (see Fig. $1 A$ ).

Although the polarization of hair cells in the PLL has been well characterized, it remains unclear how afferent neurons transmit 
information about stimulus orientation to the brain. Electrophysiological evidence suggests that afferent neurons receive inputs from hair cells of the same polarity (Obholzer et al., 2008), but the degree of specificity has not been demonstrated at the level of single synapses. In this study, we investigated whether afferent neurons distinguish hair-cell polarities as they innervate lateral-line neuromasts during normal development and after regeneration.

\section{Materials and Methods}

Zebrafish strains and husbandry. Zebrafish were maintained under standard conditions. Naturally spawned eggs were collected, cleaned, staged (Kimmel et al., 1995), and maintained in system water at $28.5^{\circ} \mathrm{C}$ at a density of 50 per 100 -mm-diameter Petri dish. Embryos were raised in system water with the addition of $200 \mu \mathrm{M}$ 1-phenyl-2-thiourea at $1 \mathrm{~d}$ postfertilization ( $\mathrm{dpf}$ ) to inhibit pigment formation. The wild-type strain used was Tübingen Long Fin. The relevant transgenic strains and their respective transgenic insertions included the following: $H u C: G F P$, $\mathrm{Tg}(\text { elavl3:EGFP })^{\text {zf8 }}$; islet1:GFP, $\mathrm{Tg}(\text { isl1:GFP })^{\text {rwo1 }}$; ET4, Et (krt4:GFP $)^{\text {sqet4 }}$; Brn3c:gap43-GFP, Tg(Brn3c:gap43-mGFP $)^{356 t ;}$ and neurogenin1, ngn1 $1^{\text {hi1059Tg }}$.

Plasmid DNA construction. To create HuC:mCherry, HuC:GFP DNA (Park et al., 2000) was digested with $\mathrm{XhoI}$ and $\mathrm{XbaI}$ to remove the green fluorescent protein (GFP)-polyA sequence. The $H u C$ promoter-containing backbone was then gel purified and ligated to an mCherry-polyA fragment that had been PCR-amplified (forward, 5'-TGCTCGAGTGCCACCATGGTGAGCAAGGGCGAGG-3'; reverse, 5' -GTCATTCTAGAGTCGCTTACAATTTACGCCTTAAG-3'). To create HuC:gap43-mCherry, the HuC: $m$ Cherry plasmid was digested with $\mathrm{XhoI}$ and ligated to annealed oligonucleotides containing a Kozak sequence and the first 20 codons of the gap 43 cDNA (forward, 5'-TCGACTGCCACCATGCTGTGCTGCATCAGAAGAACTAAACCGGTTGAGAAGAATGAAGAGGCCGATCAGGAG-3'; reverse, 5'-TCGACTCCTGATCGGCCTCTTCATTCTTCTCAACCGGTTTAGTTCTTCTGATGCAGCACAGCATGGTGGCAG-3'). To create the HuC:HRP-mCherry plasmid, the NotI site of HuC-mCherry was destroyed by blunt-end ligation, and the XhoI site was changed to a NotIAgeI site with annealed oligonucleotides. The $H R P$ - $C$ cDNA was PCR-amplified with a forward primer containing a $5^{\prime}$ EcoRI site and a reverse primer containing a $5^{\prime}$ Bam HI site (forward, $5^{\prime}$-CTGAATTCATGCAGTTAACCCCTACATTC-3'; reverse, 5'-GAGGATCCAGAGTTGCTGTTGACCACTCTGC-3'). This amplified segment of DNA was ligated into pBluescript SK + , which was subsequently digested with Bam HI and NotI. Synthesized, annealed, 5'-phosphorylated oligonucleotides encoding the transmembrane region of cadherin2 (Cdh2) followed by an AgeI site (forward, 5' -GATCCGCAGCCGGGCTGGGCACCGGAGCCATCATCGCCATACTTATCTGCATCATCATTCTGCTGGTGCTGGTGTTGATGTTTGTGATGTGGATGAAGAGACGGGATAAAGAGAGACAGACCGGTGC-3'; reverse, 5' -GGCCGCACCGGTCTGTCTCTCTTTATCCCGTCTCTTCATCCACATCACAAACATCAACACCAGCACCAGCAGAATGATGATGCAGATAAGTATGGCGATGATGGCTCCGGTGCCCAGCCCGGCTGCG-3') were ligated into the BamHI/NotI-digested Bluescript plasmid. This plasmid was subsequently digested with HindIII and EcoRI and ligated to annealed, 5'phosphorylated oligonucleotides comprising the signal sequence of $c d h 2$ with a NotI site and Kozak sequence upstream (forward, 5'-AGCTTGCGGCCGCCACCATGTACCCCTCCGGAGGCGTGATGCTGGGGCTTCTCGCCGCTCTGCAGGTGGCGGTCCAGGGCACAGGGGCGG-3'; reverse, 5'AATTCCGCCCCTGTGCCCTGGACCGCCACCTGCAGAGCGGCGAGAAGCCCCAGCATCACGCCTCCGGAGGGGTACATGGTGGCGGCCGCA- $\left.3^{\prime}\right)$. Finally, this plasmid was digested with NotI and AgeI, liberating the signal sequence-horseradish peroxidase (HRP)-transmembrane domain construct, and ligated into the NotI-AgeI sites created on the $\mathrm{HuC}$ : $m$ Cherry plasmid.

DNA injection and screening of transgenic fish. One- and two-cell embryos were pressure injected with supercoiled plasmid DNA at a concentration of $50 \mathrm{ng} / \mu \mathrm{l}$. Animals were screened at $1.5-2 \mathrm{dpf}$ for mCherry expression in the PLL nerve with a Zeiss Axioplan 2 wide-field fluorescence microscope. After selection of candidate fish with a $5 \times$ objective, definitive expression in the PLL nerve was ascertained using a $60 \times$ waterimmersion objective.

Vital labeling of hair cells. Larvae were immersed in a $200 \mu \mathrm{M}$ solution of 4-(4-(diethylamino)styryl)- $N$-methylpyridinium iodide (4-Di-2-ASP; Invitrogen) or in a $100 \mu \mathrm{M}$ solution of $N$-(3-triethylammoniumpropyl)-4-(6(4-(diethylamino)phenyl)hexatrienyl)pyridinium dibromide (FM4-64; Invitrogen) for $2 \mathrm{~min}$ at room temperature in the dark.

Live imaging of larvae. For imaging of 4-Di-2-ASP labeling, larvae were anesthetized in $625 \mu \mathrm{M} 3$-aminobenzoic acid ethyl ester methanesulfonate and imaged with a Zeiss Axioplan 2 microscope using a $5 \times$ objective lens and a CCD camera (Olympus). For confocal imaging, specimens were embedded under anesthesia in 1\% low-melting-point agarose on a glass coverslip. Images were acquired with an Ultramer Perkin-Elmer spinning-disk system on a Zeiss Axiovert 200M microscope equipped with a $63 \times, 1.4$ numerical aperture (NA) PlanApochromat objective, a Hamamatsu Orca-ER cooled CCD camera, and MetaMorph software for acquisition and analysis (MDS Analytical Technologies). Z-stacks were acquired at $1 \mu \mathrm{m}$ intervals, imaging GFP (488 nm excitation, 500-550 $\mathrm{nm}$ emission) and mCherry or FM4-64 (568 nm excitation, 590-650 nm emission). After imaging, the larvae were excised from the agarose and returned to individually marked dishes.

Hair-cell ablation. Three-day-old larvae were treated for $1 \mathrm{~h}$ with 10 $\mu \mathrm{M} \mathrm{CuSO}_{4}$ (Sigma) in system water, rinsed, and then returned to system water. The time course of recovery began when fish were removed from the $\mathrm{CuSO}_{4}$ solution.

Immunofluorescence and phalloidin staining and imaging. Fish were fixed overnight at $4{ }^{\circ} \mathrm{C}$ in PBS containing $1 \%$ Tween 20 (PBST) and $4 \%$ paraformaldehyde. Larvae were washed thrice in 1\% PBST for $1 \mathrm{~h}$ and then incubated in primary antibody or in fluorescent phalloidin. For whole-mount immunofluorescence labeling, fish were immersed overnight at $4^{\circ} \mathrm{C}$ in a 1:1000 dilution of mouse anti-acetylated $\alpha$-tubulin primary antibody (clone 6-11B-1; Sigma), washed several times in $0.2 \%$ PBST, and then incubated in a 1:200 dilution of Alexa Fluor 488conjugated secondary antibody (Invitrogen) overnight at $4^{\circ} \mathrm{C}$. The fish were washed twice for $4 \mathrm{~h}$ and stained with a 1:20 dilution of Alexa Fluor 568 phalloidin (Invitrogen) in $0.2 \%$ PBST overnight at $4^{\circ} \mathrm{C}$. They were next washed twice for $4 \mathrm{~h}$ and mounted in Vectashield (Vector Laboratories). Samples were imaged on an Olympus FV1000 laser-scanning confocal microscope with a $60 \times, 1.42 \mathrm{NA}$ PlanApochromat objective lens at a scan rate of $8 \mu$ s per pixel with Kalman averaging.

Transmission electron microscopy. Larvae were fixed at $4^{\circ} \mathrm{C}$ overnight in $400 \mathrm{~mm}$ formaldehyde, $200 \mathrm{~mm}$ glutaraldehyde, $20 \mathrm{~mm}$ sucrose, $1 \mathrm{~mm}$ $\mathrm{CaCl}_{2}$, and $90 \mathrm{~mm}$ sodium cacodylate at $\mathrm{pH}$ 7.2. The specimens were then washed in the same solution lacking the fixatives. HuC:HRP-mCherryexpressing fish were exposed to wash solution containing $1.4 \mathrm{~mm} \mathrm{3,3-}$ diaminobenzidine (Electron Microscopy Sciences) and 1\% DMSO for 5 min at room temperature, followed by the addition of $0.0042 \% \mathrm{H}_{2} \mathrm{O}_{2}$ for $5 \mathrm{~min}$. After a series of washes, specimens were postfixed in $50 \mathrm{~mm} \mathrm{OsO}_{4}$, $20 \mathrm{~mm}$ sucrose, $1 \mathrm{~mm} \mathrm{CaCl}_{2}$, and $90 \mathrm{~mm}$ sodium cacodylate at $\mathrm{pH} 7.2$ for $1.5 \mathrm{~h}$ at $4^{\circ} \mathrm{C}$. Several washes in distilled water were followed by dehydration through a series of ethanol concentrations to $95 \%$ ethanol.

Additional electron density was conferred by treatment with $0.4 \%$ uranyl acetate in $95 \%$ ethanol for $1 \mathrm{~h}$ at room temperature. The tissue was dehydrated by immersion for $2 \mathrm{~h}$ each in $100 \%$ ethanol and propylene oxide. Each specimen was impregnated with an epoxy-resin mixture (Embed-812; Electron Microscopy Sciences), placed between two nonsticking plastic coverslips (Unbreakable Cover Slips; Thermo Fisher Scientific), and heated under vacuum for $48 \mathrm{~h}$ at $50^{\circ} \mathrm{C}$ to cure the plastic.

Specimens were sectioned at a thickness of $70 \mathrm{~nm}$ with a diamond knife (Ultra $45^{\circ}$; Diatome) on an ultramicrotome (Ultracut-E; Leica). Serial sections were collected on formvar- and carbon-coated grids (Electron Microscopy Sciences) and stained for 2 min with 50\% saturated aqueous uranyl acetate in $50 \%$ acetone and for $1.5 \mathrm{~min}$ with lead citrate. Micrographs were acquired with a transmission electron microscope (G2-12 Biotwin; Tecnai FEI) equipped with a CCD camera (Hamamatsu).

Image processing. Images were analyzed and adjusted for brightness and contrast with ImageJ (NIH). For the mosaic illustration in Figure 
$1 D$, individual images were merged using Adobe Photoshop. Figures were assembled with Adobe Illustrator.

Statistical analysis. To analyze innervation bias, we scored hair cells for membrane contact with labeled neurons. When possible, hair-cell polarity was inferred at 2.5 and $3.5 \mathrm{dpf}$ from the arrangement of hair cells; at 4.5 and $5.5 \mathrm{dpf}$, hair-cell polarity was ascertained definitively by fluorescent-phalloidin staining. Neuromasts innervated by more than one labeled fiber were excluded from the analysis. We calculated the weight of evidence in favor of a statistical model in which neurons are biased in their innervation of hair cells. When reported in decibans, which are analogous to decibels in acoustics, $W=10 \times \log _{10}\left[P\left(\right.\right.$ data $\left.\mid M_{\mathrm{B}}\right) / P\left(\right.$ data $\left.\left.\mid M_{\mathrm{U}}\right)\right]$. The ratio $P\left(\right.$ data $\left.\mid M_{\mathrm{B}}\right) / P\left(\right.$ data $\left.\mid M_{\mathrm{U}}\right)$ is the Bayes factor, which indicates the support of the data for the hypothesis in which the neuron is biased, $M_{\mathrm{B}}$, versus unbiased, $M_{\mathrm{U}} \cdot P($ data $\mid M)$ is the marginal likelihood, or evidence, for hypothesis $M$. To model the data from such a biased neuron, we chose Fisher's noncentral hypergeometric distribution, with the probability of selecting one orientation of hair cell over another given by the parameter $\omega$ in the range $0-1$. For the calculation of $W$, we marginalized over $\omega$, that is, integrated over all possible values. We used a vague prior distributed as beta $(1,1)$ that is uniform and therefore convenient for computation (Fog, 2008). When we used more typically noninformative priors, such as the proper beta( $(1 / 2,1 / 2), W$ grew by $10-20 \%$; the persuasiveness of the result increased. We repeated our calculations using Wallenius's noncentral distribution, but the change in results was barely noticeable, and the qualitative answers were in agreement. The unbiased model $\left(M_{\mathrm{U}}\right)$ is a special case of both these biased models for $\omega=0.5$. In this instance, no marginalization is necessary. Because we believe that it corresponds more closely to a physiological model of neuronal activity, we report the results from Fisher's distribution.

\section{Results}

Afferent and efferent innervation of lateral-line hair cells

By $5 \mathrm{dpf}$, the PLL on each side of a larval zebrafish comprises about 10 neuromasts innervated by both afferent and efferent neurons (Fig. 1 $A-D$ ) (for review, see Dambly-Chaudière et al., 2003). Because we wished to analyze the afferent innervation in particular, we first characterized the morphology of efferent neurons so that we could reliably distinguish afferents from efferents. We examined efferent neurons labeled with GFP under the control of the islet1 promoter (Higashijima et al., 2000) and then stained hair cells at $3 \mathrm{dpf}$ with the fluorophore FM4-64 that enters them selectively through their mechanotransduction channels. The efferent axons appeared thin and featured bulbous terminals (Fig. $1 E, F)$.
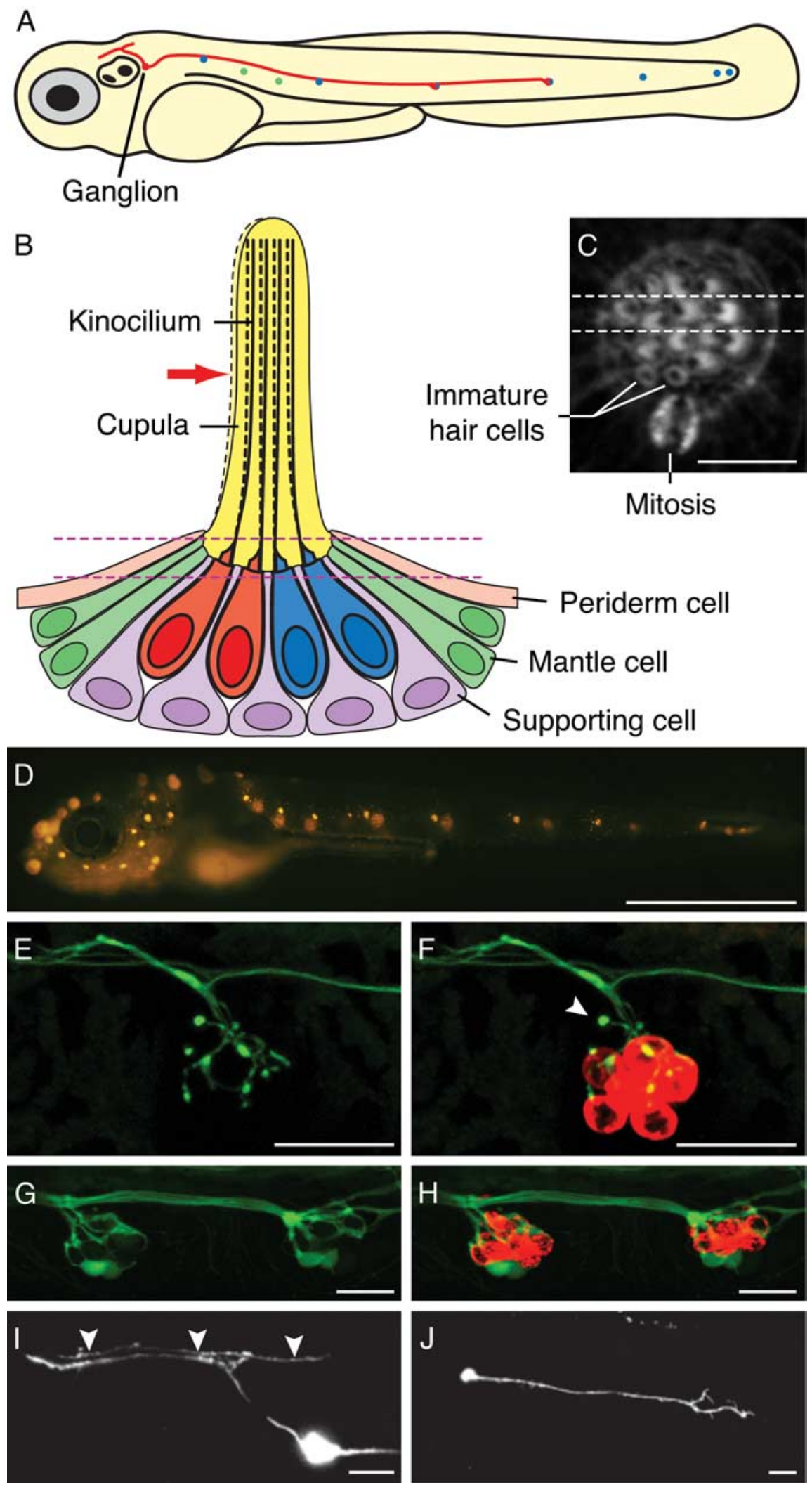

Figure 1. Structure and innervation of the lateral-line organ of a larval zebrafish. $A$, A schematic diagram of a zebrafish larva at $4 \mathrm{dpf}$ depicts seven anteroposterior neuromasts (blue) and two dorsoventral neuromasts (green) of the PLL. Additional neuromasts, which are not shown, adorn the animal's head. The soma of a single afferent neuron (red) lies in the PLL ganglion immediately caudal to the developing ear. In this example, its peripheral axon runs in the PLL nerve and contacts hair cells in two neuromasts. The central axon bifurcates and synapses in the nascent octavolateralis nucleus along the length of the hindbrain. The diameters of the neuromasts, neuronal soma, and axons are exaggerated. $\boldsymbol{B}$, Four hair cells occur at the center of a schematic depiction of a section through a single anteroposterior neuromast. Displacement of the gelatinous cupula by a hydraulic stimulus, in this instance directed toward the animal's posterior (red arrow), deflects the long kinocilia of the hair cells. (Figure legend continues.) 
To visualize afferent neurons, we examined the most caudal neuromasts of $H u C$ : GFP transgenic zebrafish, which express GFP in all neurons early in development (Park et al., 2000). By studying these terminal neuromasts before $2 \mathrm{dpf}$, we could restrict our analysis to afferents because efferent neurons do not reach this location until several hours later (Sapède et al., 2005). We found that the afferent fibers beneath each neuromast formed a dense, interlacing web that impeded the identification of fibers and of individual contacts (Fig. $1 G, H$ ).

Our inability to resolve individual afferents in a stable transgenic line necessitated the labeling of single PLL neurons by transient-expression methods, in which an arbitrary subset of neurons expressed a fluorescent protein. We injected wild-type embryos with the HuC:GFP plasmid and screened for larvae expressing GFP in the PLL nerve. Whereas lateral-line efferents have cell bodies in diencephalic and rhombencephalic nuclei (Metcalfe et al., 1985; Bricaud et al., 2001), GFP-labeled afferents possess somata in the PLL ganglion and send bifurcated axons into the hindbrain (Fig. $1 \mathrm{I}$ ). At $1.5 \mathrm{dpf}$, the neurons also feature migratory growth cones destined to innervate a subset of PLL neuromasts (Fig. $1 \mathrm{~J}$ ).

Afferent and efferent PLL neurons therefore display clear morphological differences that are discernable not only by the anatomical location of cellular structures but also by their distinct contacts with hair cells. Our preliminary results also validated a technique for the labeling of single PLL afferents that requires neither surgical manipulation nor dye application.

\section{Long-term monitoring of afferent innervation}

Each PLL neuromast contains two equal populations of hair cells with their hair bundles polarized in opposite directions (LópezSchier and Hudspeth, 2006). The orientation of these hair bundles is tightly linked to the larval bodily axes, such that the hair cells in certain neuromasts are directionally sensitive to anteriorly or posteriorly directed stimuli, whereas the hair cells in other neuromasts respond to dorsally or ventrally directed stimuli. We

\section{$\leftarrow$}

(Figure legend continued.) When communicated to the stereocilia of the hair bundles, this movement depolarizes the posteriorly polarized hair cells (red) and hyperpolarizes the anteriorly polarized cells (blue). Supporting cells separate the hair cells; mantle cells outline the neuromast and contact the periderm cells of the larva's integument. The neuromast's innervation is not shown. The parallel dashed lines depict the plane of the parasagittal optical section shown in the following panel. $\boldsymbol{C}$, A light micrograph of a neuromast's apical surface reveals the staining of filamentous actin by fluorescent phalloidin. The 20-30 stereocilia in each hair bundle form a crescent in whose concavity stands the unlabeled kinocilium. The dashed lines delineate the horizontal plane of section depicted in the preceding panel. A mitosis at the boundary between the mantle cells and supporting cells probably represents the division of an amplifying progenitor to form a mirror-symmetrical pair of hair cells. The two hair cells produced by an earlier mitosis remain immature: their hair bundles have yet to exhibit the polarization characteristic of mature hair cells. In this and all subsequent light micrographs, the animal's anterior is located to the left, and its dorsum is oriented upward. D, Labeling of hair cells in a living $6 \mathrm{dpf}$ larva with 4-Di-2-ASP reveals 11 neuromasts in the PLL on the animal's left side. The neuromasts on the right side of the transparent larva appear out of focus. $\boldsymbol{E}$, Efferent synaptic endings occur in a PLL neuromast in a living islet 1:GFP fish at $3 \mathrm{dpf}$. $\boldsymbol{F}$, Dual labeling with FM4-64 (red) demonstrates that one immature hair cell of this neuromast failed to take up the dye but was nevertheless innervated (arrowhead). G, GFP expression in the PLL nerve of a live HuC:GFP larva at $2 \mathrm{dpf}$ documents the afferent innervation of two neighboring neuromasts. $\boldsymbol{H}$, Labeling of the same specimen with FM4-64 reveals the hair cells (red). $I$, The expression of HuC:GFP in a single PLL afferent neuron reveals its soma in the PLL ganglion and its bifurcated axon reaching the hindbrain. An ascending fiber from the spinal cord is labeled as well (arrowheads). $J$, The peripheral projection of this neuron at $1.5 \mathrm{dpf}$ features an actively migrating growth cone. $\boldsymbol{D}$ is a mosaic of several images; $\boldsymbol{E}-\boldsymbol{J}$ are maximal-intensity projections of confocal Z-stacks. Scale bars: $\boldsymbol{C}, 5 \mu \mathrm{m} ; \boldsymbol{D}, 1 \mathrm{~mm} ; \boldsymbol{E}-\boldsymbol{J}, 20 \mu \mathrm{m}$. hypothesized that afferent fibers form stable synapses with hair cells of only one orientation, for such an arrangement would permit the encoding of four directions of mechanical stimulation at the first synapse of this sensory system. To test this hypothesis, we simultaneously visualized hair cells and the associated afferents in vivo by injecting the $H u C$ :mCherry expression plasmid into embryos of the strain ET4, an enhancer-trap line in which hair cells express GFP (Parinov et al., 2004).

During early larval development or hair-cell regeneration, the highly stereotyped division of a hair-cell progenitor reliably produces a pair of hair cells of opposite polarity (López-Schier and Hudspeth, 2006). When a neuromast displays mirror symmetry, it is possible to infer each hair cell's polarity based solely on its location and relationship to the other hair cells. Taking advantage of this regular pattern, we found that a single afferent neuron preferentially contacts hair cells of only one orientation. As early as $2.5 \mathrm{dpf}$, in a neuromast containing two mature hair cells, a labeled afferent fiber displayed a prominent bouton on the posteriorly polarized hair cell and a more limited contact onto the anteriorly polarized hair cell (Fig. $2 A, B$ ). One day later, the same neuromast had grown to encompass three pairs of hair cells. The three posteriorly polarized hair cells received voluminous contacts from the labeled fiber, whereas the anteriorly polarized hair cells lay near finer neurites that lacked this robust morphology (Fig. 2C-E). By $4.5 \mathrm{dpf}$, when the neuromast had grown to six hair-cell pairs, the labeled neuron innervated a commensurately greater number of hair cells (Fig. $2 \mathrm{~F}-J$ ). By this stage of development, the neuromast displayed a more complex arrangement of hair cells that no longer conformed to a plane of symmetry. To confirm the polarity of the hair cells, we fixed the fish after live imaging and labeled the actin-rich hair bundles with fluorescent phalloidin (Fig. $2 \mathrm{~K}$ ). With the consequent polarity information, we referred to the images of the living neuromast at $4.5 \mathrm{dpf}$ and determined that the three largest and oldest posteriorly polarized hair cells received bulky contacts (Fig. $2 G, H$ ). A young posteriorly polarized hair cell (Fig. $2 I$ ) and an anteriorly polarized hair cell (Fig. $2 J$ ) instead attracted only tenuous neurites.

These in vivo imaging studies suggest that each lateral-line afferent neuron forms prominent contacts selectively with hair cells of a single orientation. Furthermore, our time-lapse imaging approach revealed that afferent neurons respond continually to polarity cues as new hair cells are added to growing neuromasts.

\section{Statistical analysis of innervation bias by afferent neurons}

Although PLL afferents display a high degree of specificity in their choice of targets, they occasionally form contacts on hair cells of the opposite polarity (Fig. $2 \mathrm{~J}$ ). This finding suggested that the neurons have an inherent error rate in their choice of targets or that they can be caught in the act of interrogating a hair cell's polarity.

To provide a rigorous quantitative measure of the preference for hair-cell polarity, we devised a statistical model of bias. For each neuromast, the number of hair cells of each polarity was noted along with the number innervated by a single labeled afferent fiber (supplemental Table 1, available at www.jneurosci.org as supplemental material). Our null hypothesis was that each neuron was strictly unbiased, with no ability to discriminate between polarities of hair cells. Because there were only a handful of cells per neuromast, the deviations from the null hypothesis tended not to be statistically significant. Although we considered aggregating multiple $p$ values based on the null hypothesis alone, this procedure is of controversial validity (Goodman, 1998). We therefore addressed the issue more directly by comparing the 

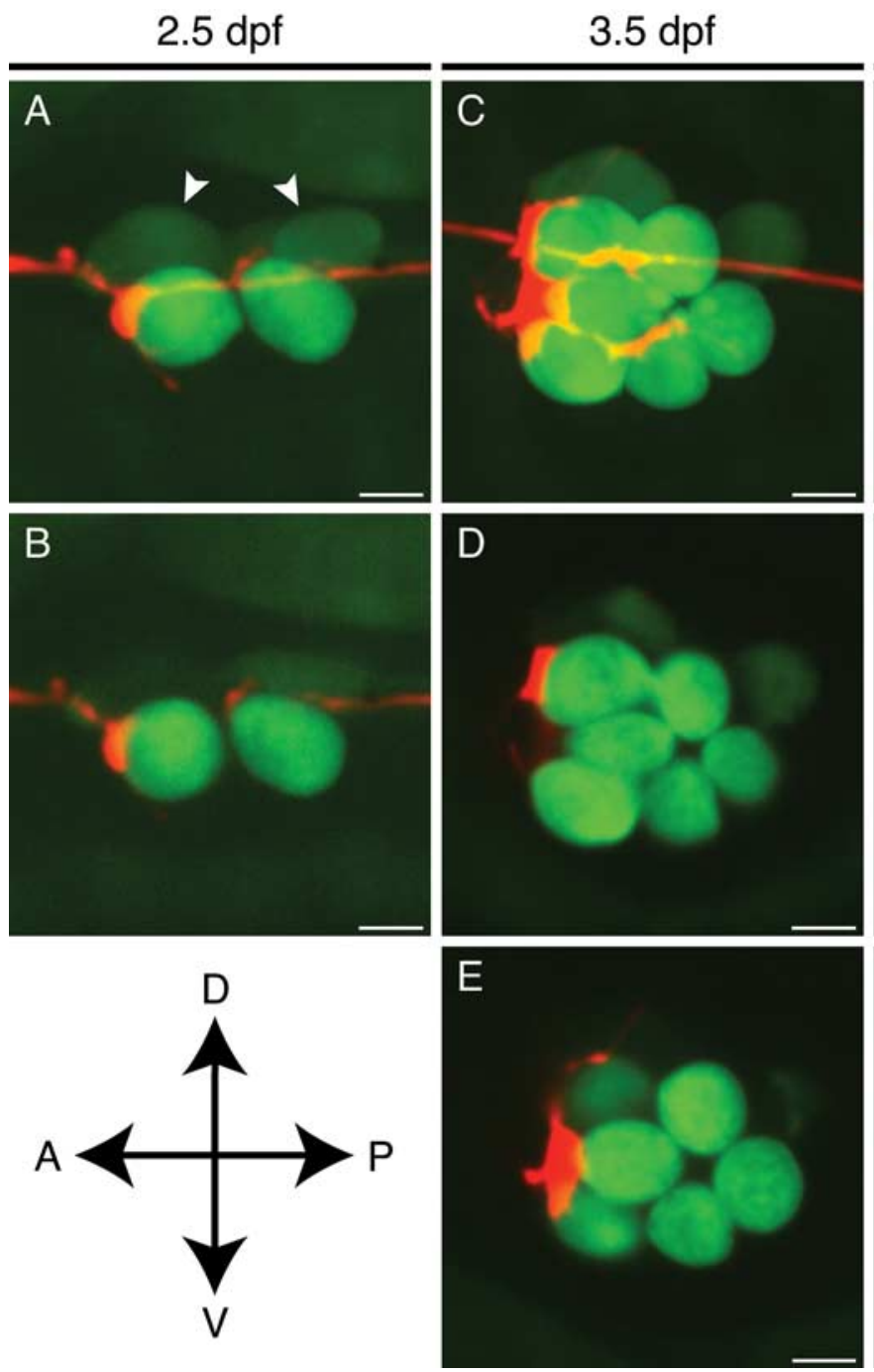
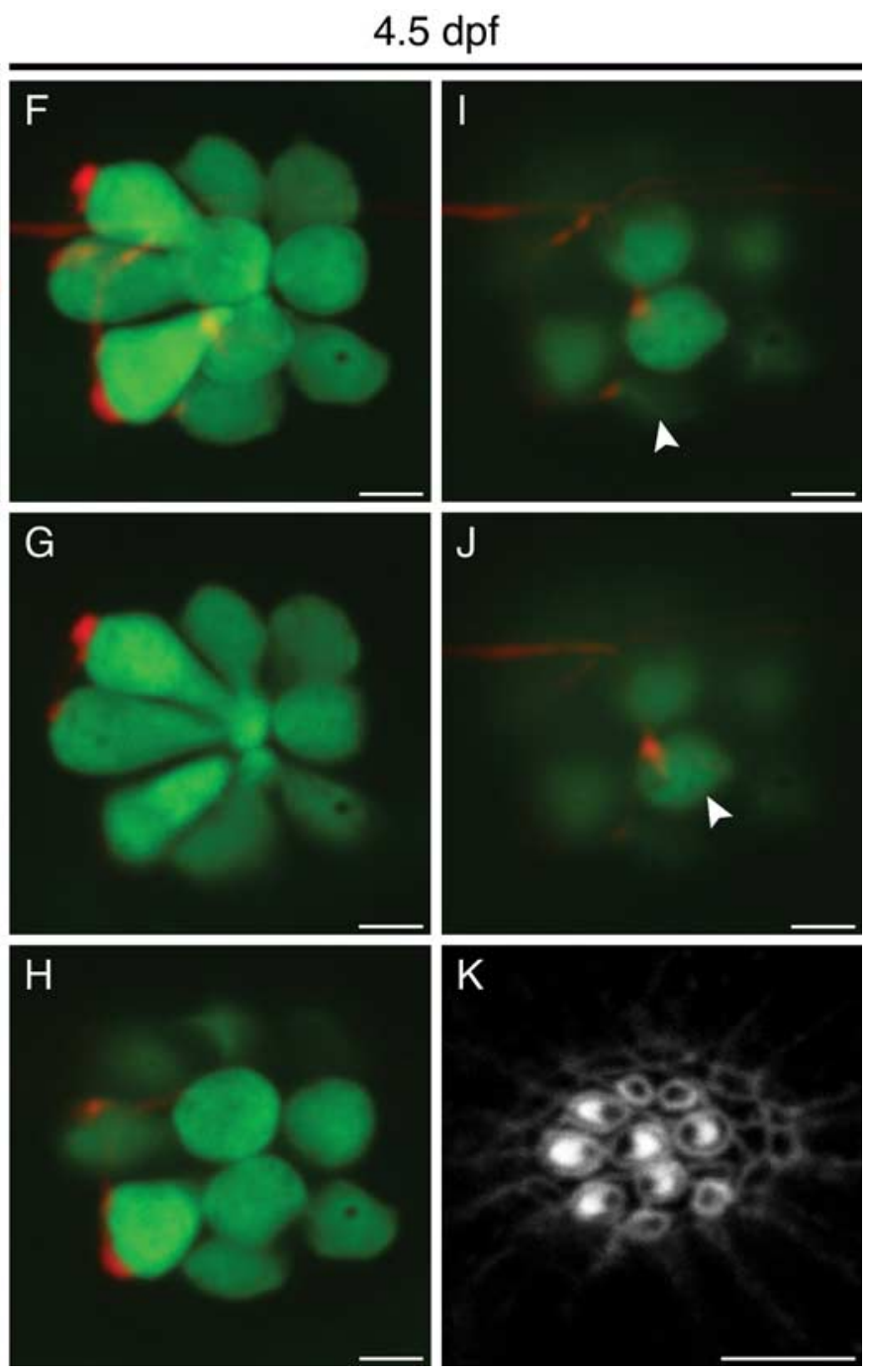

Figure 2. In vivo imaging of afferent synaptogenesis in a developing neuromast. $A$, In a maximal-intensity projection of a $Z$-stack of an anteroposterior neuromast at $2.5 \mathrm{dpf}$, an $\mathrm{mCherry-labeled}$ afferent fiber (red) forms a putative synapse with the rostralmost of the hair cells expressing GFP (green). Two immature hair cells are only dimly labeled with GFP (arrowheads). $\boldsymbol{B}$, A selected confocal section of the neuromast in $\boldsymbol{A}$ shows the extensive contact between the terminal and one hair cell as well as a substantially smaller contact with a second. $\boldsymbol{C}$, A maximal-intensity projection of the same neuromast at 3.5 dpf illustrates extensive neuronal contact with the three posteriorly polarized hair cells. D, E, Selected optical sections of the neuromast depicted in $\boldsymbol{C}$ delineate the individual contacts. $\boldsymbol{F}$, A maximal-intensity projection of the same neuromast at $4.5 \mathrm{dpf}$ demonstrates five putative synapses, of which four occur with posteriorly polarized hair cells. $\boldsymbol{G}, \boldsymbol{H}$, Large boutons have formed on the three largest posteriorly polarized hair cells. $\boldsymbol{I}$, A newly formed hair cell has been innervated (arrowhead) just as its hair bundle has begun to polarize posteriorly (see $\boldsymbol{K}$ ). $\boldsymbol{J}$, One innervated hair cell of this neuromast (arrowhead) is of the opposite polarity with respect to the others (see $\boldsymbol{K}$ ). $\boldsymbol{K}$, Staining of hair bundles in this neuromast with fluorescent phalloidin reveals the polarities of the hair cells at $4.5 \mathrm{dpf}$. The stereocilia in each bundle display a crescentic pattern of fluorescence surrounding a dark spot at the site of the kinocilium. $A$, Anterior; $P$, posterior; $D$, dorsal; $\mathrm{V}$, ventral. Scale bars, $5 \mu \mathrm{m}$.

evidence supporting the null hypothesis with that favoring the alternative hypothesis that the neurons can discriminate between polarities.

Each neuromast was assigned two probabilities that were hypothesis dependent. The first probability, which represented the alternative hypothesis, was that the pattern reflected the choices of a neuron able to discriminate between polarities with a bias parameter $\omega$ that expresses the neuron's preference of one polarity over the other. A neuron that innervates only posteriorly polarized hair cells corresponds to $\omega=1$, whereas a wholly anteriorly biased neuron has $\omega=0$. As for the toss of an unfair coin, whose probability of yielding heads is given by the probability $\omega$, any degree of bias between $\omega=0$ and $\omega=1$ is possible. The second probability reflected the null hypothesis that the neuron is strictly unbiased; in this instance, as for the toss of a fair coin, $\omega=$ $1 / 2$. Expressed in decibans, the logarithm $W$ of the ratio of these probabilities provided a quantitative measure of the evidence for bias in any neuromast (Kass and Raftery, 1995; Jaynes, 2003).

Summing the scores for the entire sample of 131 neuromasts with hair bundles polarized along the anteroposterior axis yielded $W=375 \mathrm{db}$, which corresponds to a Bayes factor of $\sim 3 \times 10^{37}$. This is a formidable weight of evidence in favor of the notion that lateral-line afferents are biased innervators: the same weight of evidence is obtained, for example, after 132 successive tosses of a coin that all result in heads, in this case favoring the coin's being double-headed instead of fair.

Plotting the distribution of bias scores with respect to larval age demonstrated that the evidence for a biased model increases with neuromast development (Fig. 3A). It should be kept in mind, however, that the evidence for bias scales with the size of a neuromast: a neuron innervating both of two anteriorly polarized hair cells and no posteriorly polarized ones, for example, 
A

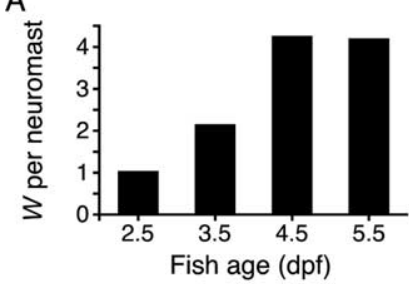

C

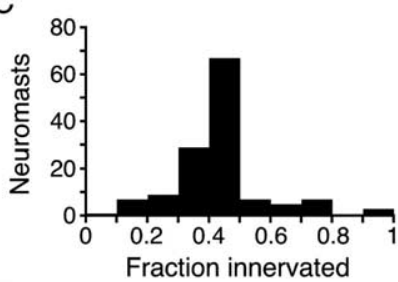

$E$

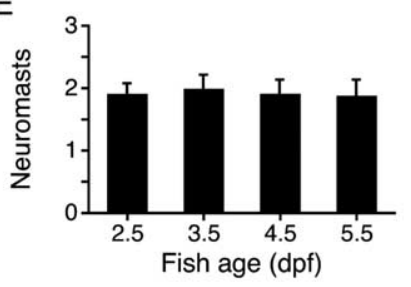

B

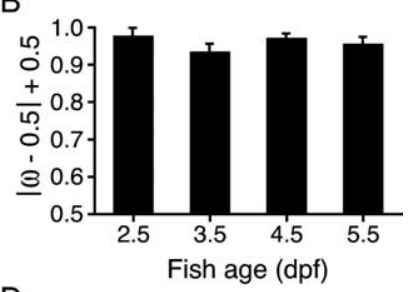

D

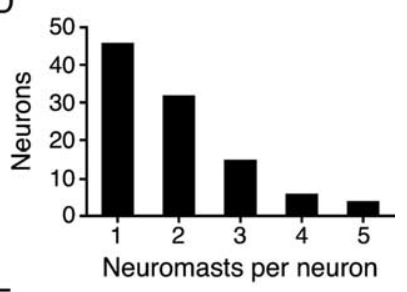

F

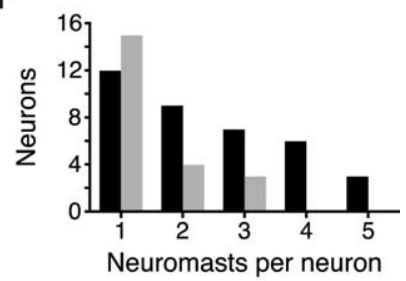

Figure 3. Statistical analysis of innervation bias and afferent neuronal receptive fields. $\boldsymbol{A}$, In a plot of the weight of evidence for a biased model ( $W$ ) against larval age, the ordinate represents the average weight of evidence contributed by a single neuromast at the given time. Summing the results over the ensemble of neuromasts yields a total weight of evidence of 375 $\mathrm{db}$. $\boldsymbol{B}$, Given that there is strong evidence for orientation selectivity, the parameter $\omega$ reflects the degree to which the neuron's choice of hair cells is biased. To illustrate the degree of bias as a function of larval age, the results have been expressed as means of the probability of $\mid \omega-$ $0.5+0.5$, so that the ordinate reflects increasing bias. The error bars represent SDs. C, A histogram illustrating the fraction of a neuromast's hair cells innervated by the labeled fiber indicates that $84 \%$ of the neuromasts studied had $50 \%$ or fewer hair cells innervated. D, A plot of the number of neurons with the indicated receptive-field sizes demonstrates the preponderance of fibers innervating one or two neuromasts. $\boldsymbol{E}$, The mean number of neuromasts innervated by a single afferent is essentially constant over the range of larval ages investigated. The error bars represent SEMs. $\boldsymbol{F}$, The distribution of neuromasts per neuron demonstrates an excess of posteriorly biased (black) over anteriorly biased (gray) neurons.

receives a lower score than a neuron innervating each of six anteriorly polarized hair cells and no posteriorly polarized ones. To evaluate the effect of the developmental increase in hair-cell numbers, we assessed the degree of bias at each time studied. To graphically represent neuronal bias, regardless of whether this bias is for anteriorly or posteriorly polarized hair cells, we plotted the mean of the probability of $|\omega-0.5|+0.5$ as a function of age and found this value to be stable over time (Fig. $3 B$ ). The observed increase in evidence for bias thus reflects neuromast growth rather than a heightened sensitivity to hair-cell polarity cues.

Because neuromasts comprise two equal populations of hair cells with opposite orientations, we expected no more than half of a neuromast's hair cells to be innervated by a labeled fiber. Indeed, $50 \%$ or fewer of the hair cells within a neuromast were innervated by the labeled afferent fiber in 113 of the 131 instances (Fig. 3C). Using a rigorous statistical test for bias in the choice of targets, we find that afferent neurons consistently innervate many, if not all, hair cells of one orientation within each neuromast.

\section{Receptive fields of single PLL afferents}

We were intrigued to find that most of the labeled afferents innervated multiple neuromasts (Fig. 3D). We asked whether each

neuron selects hair cells of a common orientation across many neuromasts, as would be required to preserve independent channels of sensory information corresponding to distinct hair-cell orientations. In each of 56 instances of multiple innervation, the afferent neuron was consistent in its preference of hair-cell polarity. In $93 \%$ of these cases, the afferent fiber innervated spatially consecutive PLL neuromasts along the tail.

The innervation of multiple neuromasts by the same neuron might be indicative of an immature pattern of connectivity that is eventually pruned to a single neuromast. We found, however, that the receptive fields of single afferent neurons persisted over the period from 2.5 to $5.5 \mathrm{dpf}$ (Fig. $3 E$ ). Although synaptic elimination may occur later in development, it is possible that the concurrent wiring of multiple sensory organs serves an essential function, such as increasing the sensitivity or signal-to-noise ratio, that is supported by a consistent choice in hair-cell polarity and by the consecutive arrangement of the neuromasts innervated.

Because there are approximately equal numbers of anteriorly and posteriorly polarized hair cells in the PLL, we were surprised to find that posteriorly polarized hair cells were disproportionately innervated by the labeled afferents. Tallying the innervated hair cells over all ages yielded 263 innervated posteriorly polarized hair cells out of a total of 460 compared with 135 innervated anteriorly polarized hair cells out of 453 . This discrepancy could not be attributed entirely to a greater ratio of hair cells to neurons, for the number of posteriorly biased neurons was proportionately increased (37 posteriorly biased versus 22 anteriorly biased). If posteriorly biased neurons more readily took up or expressed the injected DNA, our mosaic labeling method might have accounted for these disparities. Because we also found that posteriorly biased neurons were more likely to innervate multiple neuromasts (Fig. $3 F$ ), however, the excess of posteriorly biased neurons more probably reflects the existence of neuronal subtypes with divergent receptive-field properties.

\section{Specificity in dorsoventral neuromasts}

Our analysis of neuronal connectivity has thus far been limited to neuromasts containing hair cells sensitive to stimuli along the anteroposterior axis. The correlated wiring of similarly oriented hair cells might therefore reflect, not hair-cell polarity cues, but rather the anatomical arrangement of cells within the neuromast. To distinguish between these possibilities, we examined fish in which we labeled single afferents innervating dorsoventral neuromasts. In all four cases, we found a marked bias in the innervation of dorsally versus ventrally polarized hair cells (supplemental Table 1, available at www.jneurosci.org as supplemental material). Because of the more ventral location of these neuromasts (Ledent, 2002; López-Schier et al., 2004), the afferent neuron veered ventrally from the PLL nerve in its approach to the neuromast (Fig. 4A,B). Staining with fluorescent phalloidin revealed the polarities of the constituent hair cells and confirmed that four of five ventrally oriented hair cells received boutons (Fig. 4C-E). The fifth and youngest ventrally polarized hair cell was contacted by only a tenuous neurite (Fig. 4C). Despite the afferent fiber's tortuous course beneath the neuromast, the dorsally polarized hair cells apparently received no contacts.

From the examination of neuromasts sensitive to dorsally and ventrally oriented stimuli, we conclude that neuronal preference for individual hair cells depends on their polarity or on a cue normally associated with this polarity. We never encountered a neuron that innervated both a dorsoventral and an anteroposterior neuromast. 


\section{Electron microscopy of synaptic contacts}

Although our light-microscopic observations documented an orderly pattern of apposition between afferent terminals and specifically oriented hair cells, they could not unequivocally demonstrate synapses between the two. Moreover, it was unclear from the foregoing observations whether the apparent contacts are endowed with the morphological features of functional hair-cell synapses. We therefore used transmission electron microscopy to examine larval neuromasts.

Even at the earliest stage examined, 2 dpf, the hair cells contained numerous synaptic ribbons associated with synaptic vesicles and prominent presynaptic and postsynaptic densities. Our comparison of 2- and 5-d-old synaptic ribbons disclosed no striking differences between the two (Fig. $5 A, B$ ) save that the synaptic ribbons of some younger hair cells were smaller. These results confirm that hair-cell afferent synapses, or at least a substantial majority of them, are potentially competent for neurotransmitter release from as early as $2 \mathrm{dpf}$.

Our descriptive study of synaptic ultrastructure does not address whether the appositions between afferent neurons and hair cells observed in vivo are truly synapses. To directly answer this question, we sought a genetically encoded marker that labels neuronal membranes during the imaging of living cells and in correlative electron microscopy. Existing approaches, such as labeling with HRP::CD2 (Watts et al., 2004) or tetracysteine tags (Gaietta et al., 2002), possess serious drawbacks such as the need to express a fluorescent protein in parallel or to apply intense illumination in the presence of biarsenical compounds to photoconvert diaminobenzidine. To circumvent these concerns, we created a construct that encodes a single-pass transmembrane protein, HRP-mCherry, with HRP extracellularly and the fluorescent marker mCherry intracellularly (Fig. $5 C$ ). In the presence of diaminobenzidine and hydrogen peroxide, horseradish peroxidase generates a local osmiophilic precipitate visible both by light microscopy (Fig. 5D) and by electron microscopy. HRP-mCherry allows one to track the neurites of cells expressing mCherry in vivo by confocal fluorescence microscopy, then to examine regions of interest with the resolving power of transmission electron microscopy.

We injected the HuC:HRP-mCherry plasmid into larvae of the Brn3c:gap43-GFP transgenic line, in which hair-cell membranes are marked with GFP (Xiao et al., 2005). By obtaining a stack of confocal images through a neuromast at $5 \mathrm{dpf}$, we observed an mCherry-expressing afferent innervating a subset of hair cells within a neuromast (Fig. $5 E, F$ ). Although another afferent fiber was labeled as well, it expressed the marker more weakly and did not innervate this particular neuromast. We then fixed the larva and processed it to demonstrate horseradish peroxidase activity at the electron-microscopic level. After completion of the preparative protocol and embedding in plastic, the labeled neuron could be visualized under brightfield illumination (Fig. 5D). Although electron microscopy of the PLL nerve from a control larva confirmed that the afferent fibers displayed no labeling (Fig. $5 G$ ), sections from the labeled preparation revealed two afferent fibers delineated by extracellular precipitate (Fig. $5 \mathrm{H}$, arrowheads). In keeping with the mCherry fluorescence pattern, one fiber displayed substantially greater expression than the other. At higher magnification, the strongly labeled afferent was cloaked in an electron-dense precipitate that remained extracellular and did not appear to damage the neuron itself or the surrounding tissue (Fig. 5I).

To ensure that regions of membrane contact identified by fluorescence were not missed, we cut serial sections through an entire neuromast. The afferent synapses of unlabeled neurons appeared normal and lacked extracellular electron density (Fig. $5 J)$. In striking contrast, an afferent synapse corresponding to an mCherry-positive terminal (Fig. $5 E$ ) demonstrated extensive extracellular precipitate (Fig. $5 \mathrm{~K}$ ). After examining another intercellular contact (Fig. $5 F$ ), we found an afferent synapse apposed to a neuron surrounded by and filled with electron-dense material (Fig. 5L,M). This neuron appeared to have experienced extensive damage (Fig. $5 L$ ), most likely a result of gas evolution during the demonstration of horseradish peroxidase activity.

These results confirm that the contacts we observed by fluorescence microscopy indeed represent vesicle-loaded afferent synapses. Our approach has a number of advantages over other tools for correlative electron microscopy. Most notably, HRPmCherry consists of a fluorescent protein directly conjugated to a widely used enzymatic label. The result is a clearly defined fluo- 

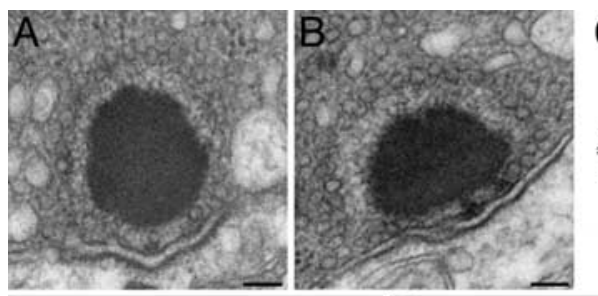

C
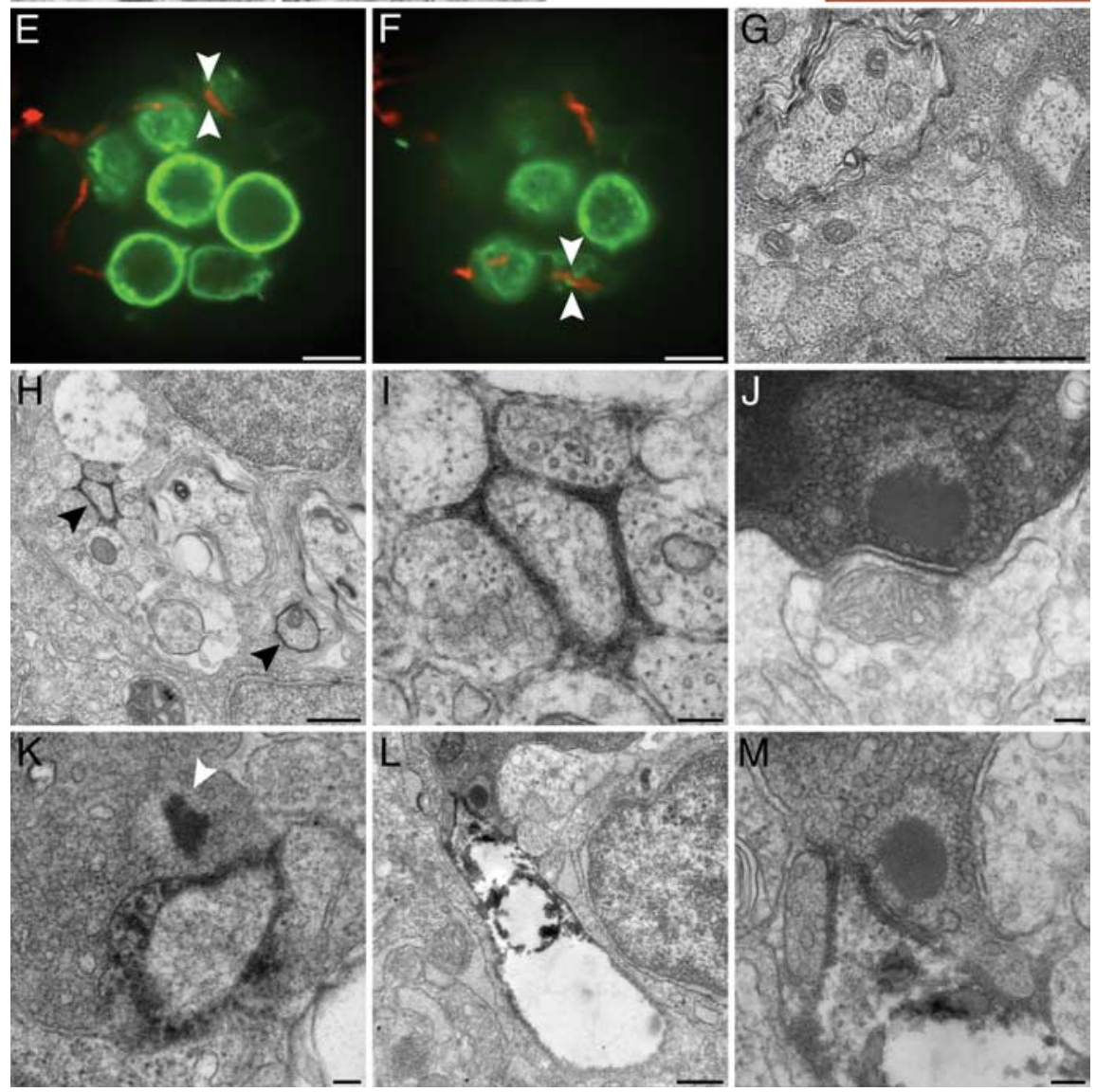

Figure 5. Correlative electron microscopy with HRP-mCherry. $\boldsymbol{A}$, A ribbon synapse in a $2 \mathrm{dpf}$ wild-type larva is indistinguishable from those in older animals. $\boldsymbol{B}$. The synapse in a $5 \mathrm{dpf}$ wild-type larva exhibits the characteristic features of a ribbon synapse, including a presynaptic dense body or ribbon, a halo of tethered synaptic vesicles, and prominent presynaptic and postsynaptic densities. C, Expression of the HRP-mCherry protein in the neurolemma places the fluorescent mCherry component intracellularly and the HRP moiety extracellularly. D, A bright-field micrograph depicts an afferent terminal expressing HRP-mCherry within a neuromast. The densely labeled fiber, which is also depicted in $\boldsymbol{E}, \boldsymbol{F}$, and $\boldsymbol{H}-\boldsymbol{M}$, is visible through the plastic resin in which the specimen has been embedded. $\boldsymbol{E}$, An optical section through a neuromast of a living Brn3c:gap43-GFP larva features hair cells expressing a membrane-localized form of GFP (green). An afferent fiber labeled with HRP-mCherry (red) innervates three of the hair cells. The region bracketed by arrowheads is examined in greater detail in $\boldsymbol{K}$. $\boldsymbol{F}$, In an optical section through the basal region of the same neuromast, arrowheads bracket a site that was later explored under the electron microscope $(\boldsymbol{L}, \boldsymbol{M})$. $\boldsymbol{G}, \mathbf{A}$ transverse section of the PLL nerve in a wild-type $5 \mathrm{dpf}$ larva demonstrates several afferent axons. $\boldsymbol{H}$, In a transverse section through a PLL nerve, two afferent fibers that express HRP-mCherry (arrowheads) produce prominent electron density in the surrounding extracellular space. The weakly labeled fiber in the lower right did not innervate the neuromast depicted in $\boldsymbol{D}-\boldsymbol{F}$ and $\boldsymbol{H}-\boldsymbol{M}$. I, A higher-magnification view of the labeled neuron at the top left of $\boldsymbol{H}$ illustrates a localized precipitate that does not damage nearby cells. $\boldsymbol{J}$, An unlabeled afferent neuron lacking electron density synapses with a hair cell of the neuromast. $\boldsymbol{K}, \mathrm{A}$ synaptic ribbon (arrowhead) in the region of membrane contact denoted by arrowheads in $\boldsymbol{E}$ verifies that the membrane contact observed by light microscopy represents an afferent synapse. $\boldsymbol{L}$, This ribbon synapse occurs at the site of membrane apposition bracketed by arrowheads in $\boldsymbol{F}$. In this instance, the neuron has become distorted and exhibits poor preservation of intracellular organelles. $\boldsymbol{M}$, Viewed at higher magnification, the ribbon synapse in $L$ illustrates the typical attributes of hair-cell afferent synapses. Scale bars: $A, B, I-K, M, 100 \mathrm{~nm} ; D-F, 5 \mu \mathrm{m} ; \boldsymbol{G}, \boldsymbol{H}, L, 500 \mathrm{~nm}$.

rescence pattern that is manifested as electron density when studied at high resolution.

\section{The preference for hair-cell polarity in regenerating neurons}

The hair cells of fish, amphibians, and birds regenerate on time scales of hours to days after extirpation by ototoxic agents such as aminoglycoside antibiotics and $\mathrm{Cu}^{2+}$ (Williams and Holder, 2000; Hernández et al., 2007). By examining how afferent neurons reinnervate neuromasts after haircell ablation, we inquired about the degree to which hair-cell polarity preferences are specified through an intrinsic affinity for a particular polarity. If afferent neurons display a polarity preference before hair-cell ablation, do they maintain that preference after newly minted hair cells have repopulated the neuromast, or is the polarity preference reset? In the latter instance, afferents would be expected to innervate hair cells of either polarity after regeneration, with no memory of the preablation preference.

We injected DNA encoding membrane-targeted mCherry driven by the $H u C$ promoter (HuC:gap43-mCherry) into stably transgenic embryos bearing the Brn3c:gap43-GFP transgene. After screening for larvae that expressed mCherry in PLL neurons, we imaged the innervated neuromasts at $3 \mathrm{dpf}$. At this stage, neuromasts are small enough to display an unambiguous axis of mirror symmetry, so that the polarities of hair cells are certain (Fig. 6A). The afferent fiber innervated all four posteriorly polarized hair cells and none of the anteriorly polarized hair cells, indicating a marked preference for the former. Immediately after imaging, we immersed the fish in $10 \mu \mathrm{M} \mathrm{CuSO}$ solution to eliminate lateral-line hair cells. Two hours after this treatment, we examined the same neuromast again and found it to be devoid of hair cells (Fig. 6B). In conjunction with the loss of hair cells, the labeled neuron underwent considerable retraction of its terminals.

As the neuromast repopulated its hair cells over the next $46 \mathrm{~h}$, the afferent neuron extended its neurites and formed synapses anew (Fig. $6 C-K$ ). After $6 \mathrm{~h}$, a centrally positioned cell began to express GFP and probably represented a hair-cell progenitor that would give rise to two daughter hair cells (López-Schier and Hudspeth, 2006). By $12 \mathrm{~h}$ after treatment, the neuromast contained two mature hair cells; the posteriorly polarized hair cell received a small contact from the labeled afferent fiber, which grew more pronounced by $24 \mathrm{~h}$. At $36 \mathrm{~h}$, the neuromast had grown to encompass seven hair cells, of which the nerve appeared to contact only three (Fig. $6 F, G)$. At this stage of neuromast recovery, it was impossible to reliably infer the hair-bundle polarity without phalloidin staining. Finally, $48 \mathrm{~h}$ after ablation, the neuromast contained eight mature hair cells, as well as two immature hair cells at its rostral extreme. Phalloidin staining revealed the presence of four anteriorly polarized and four posteriorly polar- 
ized hair cells, and we ascertained that the labeled neuron had formed synapses with all four of the latter (Fig. $6 H-L$ ). In contrast, two of the four anteriorly polarized hair cells were contacted by thin neurites (Fig. $6 \mathrm{H}$, J, arrowheads) that differed significantly from the larger boutons on the posteriorly polarized hair cells. Repeating this protocol in three additional animals yielded results consistent with this representative example for both anteriorly and posteriorly biased neurons.

This experimental approach has elucidated two important properties of this system. First, afferent fibers recover and reinnervate neuromasts after acute injury on a time scale that largely matches that of haircell regeneration. Second, afferent fibers evidently remember the polarity of the hair cells that they innervated before ablation. This consistency in the preference for hair-cell polarity led us to question whether the neuron passively interprets hair-cell polarity cues or plays an instructive role in determining hair-cell polarity. To distinguish between these possibilities, we determined the polarities of hair cells in neurogenin 1 mutant zebrafish, which lack the PLL nerve and possess supernumerary neuromasts (Grant et al., 2005; LópezSchier and Hudspeth, 2005). The neuromast hair cells of mutant larvae were polarized normally across a plane of mirror symmetry despite the complete absence of the PLL nerve (Fig. 7), ruling out a scenario in which the neuron dictates haircell polarities.

\section{Discussion}

Our in vivo time-lapse imaging revealed that each lateral-line afferent neuron specifically contacts hair cells of a common hair-bundle polarity within a neuromast and across multiple consecutive neuromasts. Because these studies relied on membrane propinquity alone to signal the presence of intercellular contacts, we created a reagent, HRP-mCherry, that allowed us to confirm that fluorescently marked contacts correspond at the electron-microscopic level to synapses between hair cells and afferent terminals. Finally, we examined the reestablishment of neuronal connectivity after hair-cell ablation and found that afferents promptly resume contact with regenerating hair cells of the same polarity as those innervated originally.

\section{The receptive fields of single afferent neurons}

Before this study, electrophysiological evidence had suggested that lateral-line afferents synapse with hair cells of the same polarity. The bipartite pattern of action potential firings in nerve
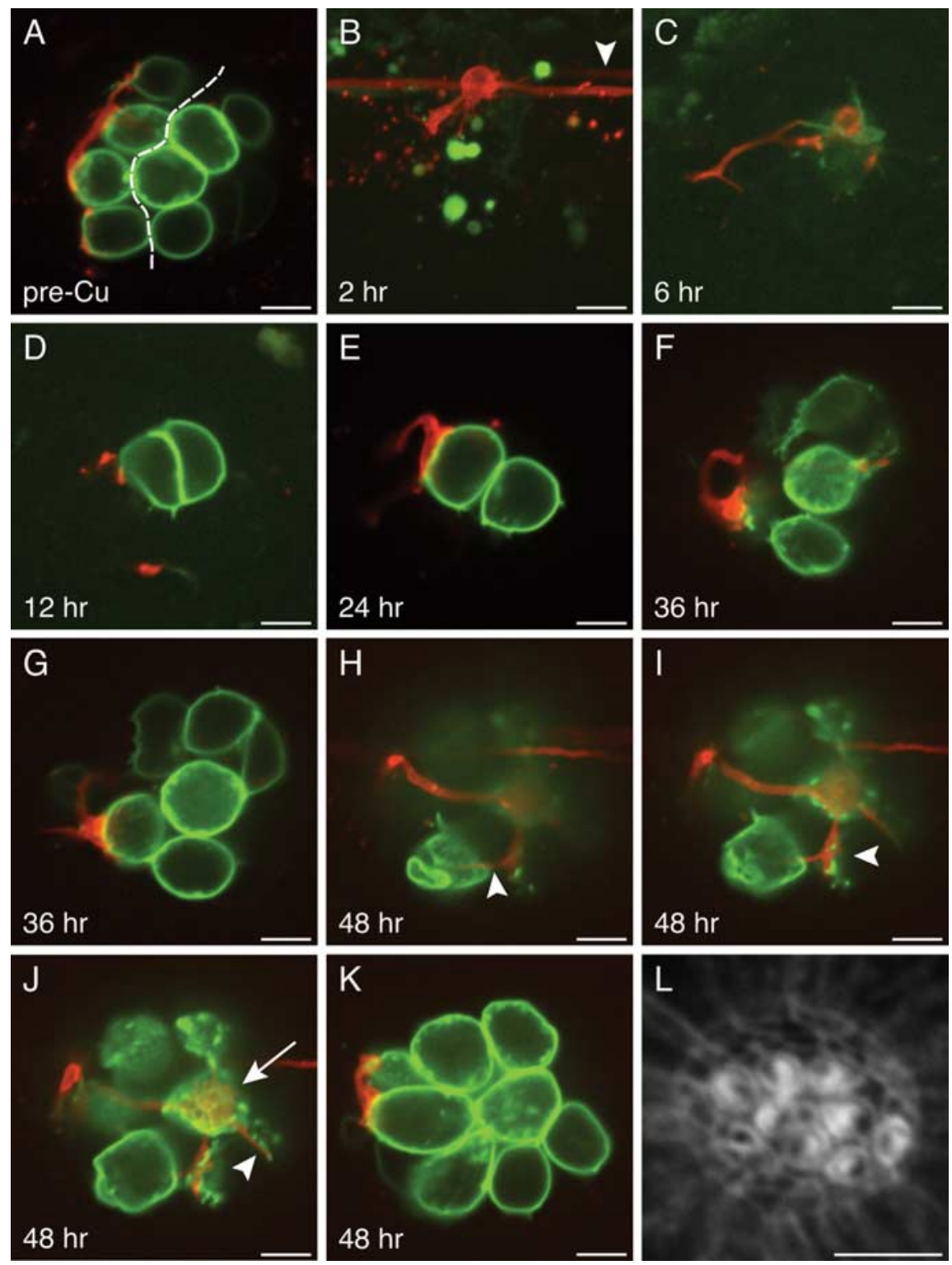

Figure 6. Reinnervation of regenerated hair cells. $A$, In an optical section through a 3 dpf neuromast before hair-cell elimination, the axis of planar cellular polarity (dashed line) can be inferred from the positions of the constituent hair cells. The afferent fiber has selectively synapsed with posteriorly polarized hair cells. $\boldsymbol{B}$, In a maximal-intensity projection of the same neuromast $2 \mathrm{~h}$ after the application of $10 \mu \mathrm{m} \mathrm{Cu}{ }^{2+}$, the hair cells have been eliminated, and the neuron has retracted its terminals. Note the presence in the lateral-line nerve of another labeled neuron that does not innervate this neuromast (arrowhead). $C, A f t e r 6 h$, the neuromast contains one weakly fluorescent progenitor that has not yet undergone mitosis to form two new hair cells. D, Twelve hours after $\mathrm{Cu}^{2+}$ treatment, the newly formed posteriorly polarized hair cell receives a small synapse. $\boldsymbol{E}$, By $24 \mathrm{~h}$, the synapse depicted in $\boldsymbol{D}$ has grown in size and in the extent of membrane contact. $\boldsymbol{F}, \boldsymbol{G}, \mathrm{At} 3 \mathbf{6} \mathrm{h}$ after treatment, the neuron appears to contact two or three hair cells, but their polarities cannot be inferred because of the complex organization of the neuromast. It is likely, however, that the synapse depicted in $\mathbf{G}$ is identical to that in $\boldsymbol{D}$ and $\boldsymbol{E} . \boldsymbol{H}-\boldsymbol{K}, \mathrm{By} 48 \mathrm{~h}$, the neuromast has grown to encompass eight mature hair cells with polarized hair bundles (see $\boldsymbol{L}$ ). These four panels are ordered from the bases to the apices of the hair cells. $\boldsymbol{H}$, A thin neurite reaches an anteriorly polarized hair cell (arrowhead). $I$, A larger bouton contacts the ventralmost of the posteriorly polarized hair cells (arrowhead). J, A synaptic contact blankets the basal surface of a posteriorly polarized hair cell (arrow), whereas only a tenuous process reaches an anteriorly polarized hair cell (arrowhead). $\boldsymbol{K}$, The afferent neuron forms voluminous boutons on two posteriorly polarized hair cells. $L$, Staining with fluorescent phalloidin $48 \mathrm{~h}$ after treatment defines the polarities of the 10 hair bundles. Scale bars, $5 \mu \mathrm{m}$.

recordings from the Xenopus lateral line reflects the afferent wiring of two populations of hair cells with opposite polarity (Görner, 1963). Single-neuron recordings from the PLL ganglion of zebrafish have more recently demonstrated the receptive field to be confined to unidirectional mechanical stimuli (Obholzer et al., 2008). Our findings provide direct anatomical evidence that each 

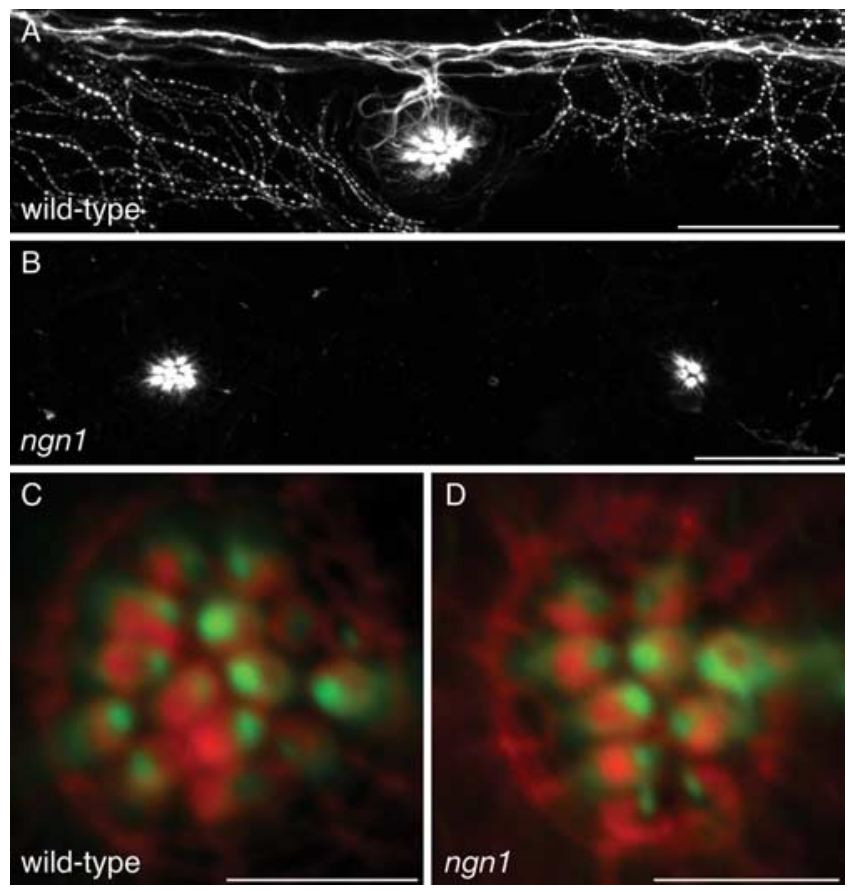

Figure 7. Hair-cell polarity in the absence of innervation. $\boldsymbol{A}, \mathrm{A}$ maximal-intensity projection of a confocal Z-stack depicts immunolabeling for acetylated $\alpha$-tubulin in the lateral line of a 5 $\mathrm{dpf}$ wild-type larva. The PLL nerve and superficial sensory neurons are labeled, as well as microtubules in the apices of hair cells. $\boldsymbol{B}$, Immunolabeling of a neurogenin1 mutant sibling for acetylated $\alpha$-tubulin illustrates the absence of a PLL nerve. Labeling persists in the microtubules of hair cells. $\boldsymbol{C}$, Staining of a wild-type neuromast with fluorescent phalloidin (red) and immunofluorescent labeling of acetylated $\alpha$-tubulin (green) reveal the polarities of the hair bundles in this anteroposterior neuromast. $\boldsymbol{D}$, The hair-bundle polarities of a neurogenin $1 \mathrm{mu}-$ tant neuromast are unperturbed despite the lack of innervation. Scale bars: $\boldsymbol{A}, \boldsymbol{B}, 30 \mu \mathrm{m} ; \boldsymbol{C}, \boldsymbol{D}, 5$ $\mu \mathrm{m}$.

afferent fiber contacts hair cells of the same polarity and a statistical demonstration of the consistence of this pattern.

We noted that the majority of afferent neurons stably innervate several neuromasts (Fig. $3 D, E$ ). This represents a more extreme version of the pattern seen in amphibians, in which only a fraction of afferent fibers innervate multiple stitches of clustered neuromasts (Fritzsch, 1989; Mohr and Görner, 1996). The variability in the sizes of receptive fields in the zebrafish PLL casts doubt on whether the primary purpose of this sensory system is a fine-grained mapping of the periphery through a one-to-one allocation of afferents to neuromasts. The innervation of multiple neuromasts may represent a compromise that boosts the sensitivity of the system through the binning of adjacent inputs. It is reassuring that afferents rarely innervate nonconsecutive neuromasts, for this would place a seemingly unnecessary burden on the establishment of an appropriate pattern of neural connections.

Somatotopy, the mapping of sensory inputs to corresponding positions in the brain, has been demonstrated in the central projection of the lateral-line nerve of larval zebrafish (Alexandre and Ghysen, 1999; Gompel et al., 2001). Compared with anterior lateral-line neurons, PLL neurons project to a more dorsomedial position in the hindbrain (Alexandre and Ghysen, 1999). A PLL neuron extends its central axon before neuromast innervation, and the position of the target neuromast can be predicted from the morphology of the growth cone (Gompel et al., 2001). These findings suggest a marked degree of intrinsic patterning before synaptic contact with hair cells. With this in mind, we scrutinized neurons innervating multiple neuromasts to learn whether these neuromasts were coinnervated in any reproducible pattern. For example, do the fifth and sixth neuromasts of the larval PLL always wire together? Except for the terminal neuromasts located on the caudal tailfin, we found no consistent pattern of coinnervation, so it remains possible that some flexibility in neuromast choice exists and that the prepatterning of afferents guides but does not strictly determine this choice.

\section{HRP-mCherry, a tool for correlative electron microscopy}

Because specialized organelles regulate neurotransmitter release, evidence of intercellular contact is insufficient to infer the presence of a synapse. We therefore developed HRP-mCherry to provide direct evidence that sites of membrane contact between hair cells and afferent neurons represent functional synapses (Fig. $5 E, F, K-M)$. Horseradish peroxidase requires glycosylation for its enzymatic activity (Veitch, 2004), so we designed a fusion protein in which the enzyme moiety is situated at the $\mathrm{N}$ terminus and is directed across the membrane by a signal peptide. Linkage of the fluorescent protein mCherry to the extracellular horseradish peroxidase by the transmembrane region of $\mathrm{N}$-cadherin then allows fluorescent as well as electron-microscopic labeling of specific cells.

This approach offers a significant improvement over previously available techniques for correlating neurolemmal fluorescence in vivo with electron-dense precipitates, such as tetracysteine tags or CD2::HRP. Tetracysteine tags require the use of potentially toxic arsenical compounds as well as sharply focused illumination, which precludes the uniform labeling of lengthy cellular processes. Unlike HRP-mCherry, CD2::HRP necessitates the coexpression of a fluorescent protein, which may be inconvenient and provides no stoichiometric relation between fluorescence intensity and electron density. The extracellular reaction product of HRP-mCherry does not interfere with the observation of organelles within a labeled cell. Although the reaction product diffuses somewhat, labeling is sufficiently circumscribed that the identity of a labeled cell is clear (Fig. $5 H, I$ ).

\section{Synaptic-target selection by developing afferent neurons}

Although an obvious requirement for the proper functioning of sensory circuits is that neurons form synapses with the appropriate targets, we lack a comprehensive understanding of the factors that guide the choice of target cells (Benson et al., 2001; Waites et al., 2005). We have illustrated an experimental preparation that facilitates the study of synaptogenesis through noninvasive optical techniques in a living vertebrate. An attractive feature of this system is that an experimenter may readily determine relevant properties of both presynaptic and postsynaptic cells. For the hair cell, it is possible to ascertain the position on the larval surface and the axis of mechanosensitivity. For the afferent neuron, one can observe the complement of neuromasts innervated, the specific hair cells selected, and the pattern of axon projections in the hindbrain. These features permit the study of synaptogenesis at the resolution of individual contacts in a system that is amenable to experimental manipulation, properties usually associated with neuronal cultures or invertebrate organisms.

A noteworthy aspect of this experimental system is the temporal course of synaptic target selection and stabilization. The evidence for polarity bias was strong at every time examined, and we detected no significant change in the degree of bias (Fig. $3 A, B)$. This result suggests that the neurons respond to polarity cues throughout neuromast growth and turnover. This conclusion contrasts with that for sensory circuits in which there are 
distinct periods of exuberant synaptogenesis and activitydependent synaptic elimination, such as occurs in the mammalian visual system (Luo and O’Leary, 2005).

\section{The mechanism of synaptic specificity}

The wiring specificity documented here could arise if the afferent neurons instruct hair cells to assume a certain polarity. Because the hair bundles of mutant animals lacking the PLL nerve are polarized normally (Fig. 7), however, this mechanism is unlikely. Another possibility is that a polarity signal within the neuromast dictates both the polarity of the hair cells and the synaptic targets of the neurons. One argument against this arrangement comes from large neuromasts with multiple planes of mirror symmetry, in which hair cells of opposing polarities are extensively intermixed. A neuron contacts all the hair cells of a specific polarity regardless of their location within such a neuromast (Fig. 6I,J). The consistent choice of hair-cell polarity across several neuromasts provides a second piece of evidence, for it is difficult to understand how an individual fiber would receive the same polarization instructions as it entered distinct neuromasts.

The most likely possibility, and one that is consistent with all of our observations, is that afferent neurons have a capacity to sense the polarity of the hair cells and synapse accordingly. Mechanisms of this sort can be divided into two broad and potentially overlapping categories (Cline, 2003): those that require synaptic activity and those that do not. Although we cannot rule out either possibility, our data provide some initial clues and permit us to outline future studies to determine the underlying mechanism. The consistent polarity preference of afferent fibers before and after hair-cell elimination (Fig. 6) is interesting in this regard. If afferents behave as detectors of coincident synaptic release, then the choice of hair-cell polarity after reinnervation should be determined by the polarity of the first hair cell encountered. Because this was not observed, it is likely that afferents are specified to prefer a certain polarity or that, once a preference has been established, afferents remain committed to this polarity even after hair-cell ablation.

The availability of tools to manipulate electrical activity in selected cell types in vivo will permit further investigation into the processes involved. Using hair cell-specific promoters, one may constitutively silence synaptic activity by expressing the inwardly rectifying potassium channel Kir2.1 (Burrone et al., 2002) or temporally modulate synaptic release with Chlamydomonas channelrhodopsin-2 or Natronomonas halorhodopsin (Nagel et al., 2003; Zhang et al., 2007). The same approaches could also be used to investigate how afferent receptive fields are established. For example, afferent fibers might compete for neuromasts and hair cells in an activity-dependent manner similar to that observed for retinal ganglion cells in the optic tectum (Hua et al., 2005). By delineating the molecular processes responsible for the establishment of synaptic specificity, this approach should shed light on the mechanism by which sensory systems decompose environmental stimuli in the periphery and then recapitulate the richness of sensory information in the brain.

\section{References}

Alexandre D, Ghysen A (1999) Somatotopy of the lateral line projection in larval zebrafish. Proc Natl Acad Sci U S A 96:7558-7562.

Benson DL, Colman DR, Huntley GW (2001) Molecules, maps and synapse specificity. Nat Rev Neurosci 2:899-909.

Bricaud O, Chaar V, Dambly-Chaudière C, Ghysen A (2001) Early efferent innervation of the zebrafish lateral line. J Comp Neurol 434:253-261.

Burrone J, O’Byrne M, Murthy VN (2002) Multiple forms of synaptic plas- ticity triggered by selective suppression of activity in individual neurons. Nature 420:414-418.

Cline H (2003) Sperry and Hebb: oil and vinegar? Trends Neurosci 26:655-661.

Dambly-Chaudière C, Sapède D, Soubiran F, Decorde K, Gompel N, Ghysen A (2003) The lateral line of zebrafish: a model system for the analysis of morphogenesis and neural development in vertebrates. Biol Cell 95:579-587.

Dickson BJ (2002) Molecular mechanisms of axon guidance. Science 298:1959-1964.

Flock $\AA$, Wersäll J (1962) A study of the orientation of the sensory hairs of the receptor cells in the lateral line organ of fish, with special reference to the function of the receptors. J Cell Biol 15:19-27.

Fog A (2008) Calculation methods for Wallenius' noncentral hypergeometric distribution. Comm Stat Simul Comp 37:258-273.

Fritzsch B (1989) Diversity and regression in the amphibian lateral line and electrosensory system. In: The mechanosensory lateral line: neurobiology and evolution (Coombs S, Görner P, Münz H, eds). New York: Springer.

Gaietta G, Deerinck TJ, Adams SR, Bouwer J, Tour O, Laird DW, Sosinsky GE, Tsien RY, Ellisman MH (2002) Multicolor and electron microscopic imaging of connexin trafficking. Science 296:503-507.

Gompel N, Dambly-Chaudière C, Ghysen A (2001) Neuronal differences prefigure somatotopy in the zebrafish lateral line. Development 128:387-393.

Goodman CS, Shatz CJ (1993) Developmental mechanisms that generate precise patterns of neuronal connectivity. Cell 72 [Suppl]:77-98.

Goodman SN (1998) Multiple comparisons, explained. Am J Epidemiol 147:807-812.

Görner P (1963) Untersuchungen zur Morphologie und Elektrophysiologie des Seitenlinienorgans vom Krallenfrosch (Xenopus laevis Daudin). Z Vergl Physiol 47:316-338.

Grant KA, Raible DW, Piotrowski T (2005) Regulation of latent sensory hair cell precursors by glia in the zebrafish lateral line. Neuron 45:69-80.

Hernández PP, Olivari FA, Sarrazin AF, Sandoval PC, Allende ML (2007) Regeneration in zebrafish lateral line neuromasts: expression of the neural progenitor cell marker sox2 and proliferation-dependent andindependent mechanisms of hair cell renewal. Dev Neurobiol 67:637-654.

Higashijima S, Hotta Y, Okamoto H (2000) Visualization of cranial motor neurons in live transgenic zebrafish expressing green fluorescent protein under the control of the islet-1 promoter/enhancer. J Neurosci 20:206-218.

Hua JY, Smear MC, Baier H, Smith SJ (2005) Regulation of axon growth in vivo by activity-based competition. Nature 434:1022-1026.

Hudspeth AJ (1989) How the ear's works work. Nature 341:397-404.

Jaynes ET (2003) Probability theory: the logic of science. Cambridge, UK: Cambridge UP.

Kass RE, Raftery AE (1995) Bayes factors. J Am Stat Assoc 90:773-795.

Keen EC, Hudspeth AJ (2006) Transfer characteristics of the hair cell's afferent synapse. Proc Natl Acad Sci U S A 103:5537-5542.

Kimmel CB, Ballard WW, Kimmel SR, Ullmann B, Schilling TF (1995) Stages of embryonic development of the zebrafish. Dev Dyn 203:253-310.

Ledent V (2002) Postembryonic development of the posterior lateral line in zebrafish. Development 129:597-604.

López-Schier H, Hudspeth AJ (2005) Supernumerary neuromasts in the posterior lateral line of zebrafish lacking peripheral glia. Proc Natl Acad Sci U S A 102:1496-1501.

López-Schier H, Hudspeth AJ (2006) A two-step mechanism underlies the planar polarization of regenerating sensory hair cells. Proc Natl Acad Sci U S A 103:18615-18620.

López-Schier H, Starr CJ, Kappler JA, Kollmar R, Hudspeth AJ (2004) Directional cell migration establishes the axes of planar polarity in the posterior lateral-line organ of the zebrafish. Dev Cell 7:401-412.

Luo L, O'Leary DD (2005) Axon retraction and degeneration in development and disease. Annu Rev Neurosci 28:127-156.

Metcalfe WK, Kimmel CB, Schabtach E (1985) Anatomy of the posterior lateral line system in young larvae of the zebrafish. J Comp Neurol 233:377-389.

Mohr C, Görner P (1996) Innervation patterns of the lateral line stitches of 
the clawed frog, Xenopus laevis, and their reorganization during metamorphosis. Brain Behav Evol 48:55-69.

Montgomery JC, Baker CF, Carton AG (1997) The lateral line can mediate rheotaxis in fish. Nature 389:960-963.

Nagel G, Szellas T, Huhn W, Kateriya S, Adeishvili N, Berthold P, Ollig D, Hegemann P, Bamberg E (2003) Channelrhodopsin-2, a directly lightgated cation-selective membrane channel. Proc Natl Acad Sci U S A 100:13940-13945.

Obholzer N, Wolfson S, Trapani JG, Mo W, Nechiporuk A, Busch-Nentwich E, Seiler C, Sidi S, Söllner C, Duncan RN, Boehland A, Nicolson T (2008) Vesicular glutamate transporter 3 is required for synaptic transmission in zebrafish hair cells. J Neurosci 28:2110-2118.

Parinov S, Kondrichin I, Korzh V, Emelyanov A (2004) Tol2 transposonmediated enhancer trap to identify developmentally regulated zebrafish genes in vivo. Dev Dyn 231:449-459.

Park HC, Kim CH, Bae YK, Yeo SY, Kim SH, Hong SK, Shin J, Yoo KW, Hibi M, Hirano T, Miki N, Chitnis AB, Huh TL (2000) Analysis of upstream elements in the $\mathrm{HuC}$ promoter leads to the establishment of transgenic zebrafish with fluorescent neurons. Dev Biol 227:279-293.

Sapède D, Rossel M, Dambly-Chaudière C, Ghysen A (2005) Role of SDF1 chemokine in the development of lateral line efferent and facial motor neurons. Proc Natl Acad Sci U S A 102:1714-1718.

Shotwell SL, Jacobs R, Hudspeth AJ (1981) Directional sensitivity of individual vertebrate hair cells to controlled deflection of their hair bundles. Ann N Y Acad Sci 374:1-10.

Veitch NC (2004) Horseradish peroxidase: a modern view of a classic enzyme. Phytochemistry 65:249-259.

Waites CL, Craig AM, Garner CC (2005) Mechanisms of vertebrate synaptogenesis. Annu Rev Neurosci 28:251-274.

Watts RJ, Schuldiner O, Perrino J, Larsen C, Luo L (2004) Glia engulf degenerating axons during developmental axon pruning. Curr Biol 14:678-684.

Williams JA, Holder N (2000) Cell turnover in neuromasts of zebrafish larvae. Hear Res 143:171-181.

Xiao T, Roeser T, Staub W, Baier H (2005) A GFP-based genetic screen reveals mutations that disrupt the architecture of the zebrafish retinotectal projection. Development 132:2955-2967.

Zhang F, Wang LP, Brauner M, Liewald JF, Kay K, Watzke N, Wood PG, Bamberg E, Nagel G, Gottschalk A, Deisseroth K (2007) Multimodal fast optical interrogation of neural circuitry. Nature 446:633-639. 